\title{
Abbreviations of names of organizations used frequently
}

\section{Romania}

BNS National Union Bloc (Blocul Naţional Sindical)

Cartel National Trade Union Confederation 'Cartel Alfa', Romania (Confederația

Alfa Sindicală Națională 'Cartel Alfa')

CNSLR- National Confederation of Free Trade Unions of Romania - Brotherhood

Frăţia (Confederația Natională a Sindicatelor Libere din România-Frăţia)

COS Special Steelworks (Combinatul de Oțeluri Speciale)

CSR Reşița Steelworks, Romania (Combinatul Siderurgic Reşița)

Metarom Trade Union Federation of Steelworkers, Romania (Federația Naţională a

Siderurgiştilor - Metarom)

SLI Free Independent Union (Sindicatul Liber Independent)

SVS Union 'Virgil Săhleanu' Solidarity (Solidaritatea 'Virgil Săhleanu')

UGSR General Union of Romanian Syndicates (Uniunea Generală a Sindicatelor din România)

\section{Ukraine}

ASMU Auto- and Farm Machine-Building Workers' Union of Ukraine (Profspilka pratsivnykiv avtomobil'nogo ta sil's'kogospodar'skogo mashynobuduvannia Ukrainy)

BTS Belotserkovsel'mash, the company that owns the HMZ plant

BYUT Yulia Tymoshenko Bloc, Ukraine (Blok Yulii Tymoshenko)

KVPU Confederation of Free Trade Unions of Ukraine (Konfederatsiia vil'nykh profspilok Ukrainy)

FNPR The Federation of Independent Trade Unions of Russia (Federatsiya nezavisimykh profsoyuzov Rossii)

FPU Federation of Trade Unions of Ukraine (Federatsiya profspilok Ukrainy)

HK Kherson Combine Plant (Khersons'ki Kombainy)

HMZ Kherson Machine-Building Plant (Khersons'kyi mashinobudivnyi zavod)

KPU Communist Party of Ukraine (Komunistychna partiia Ukrainy)

KrAZ Kremenchuk Automobile-Producing Plant (Kremenchuks'kyi avtomobilebudivel'nyi Zavod)

NPGU Independent Trade Union of Miners of Ukraine (Nezalezhna profspilka hirnykiv Ukrainy) 
TKZ Ternopil' Harvester Plant (Ternopil'skyi kombainovyi zavod)

VPZ Vinnitsa Ball-Bearings Plant (Vinnits'kyi pidshipnikovyi zavod)

ZAZ The Zaporizhia Automobile-Building Plant (Zaporiz'kyi avtomobilebudivel'nyi zavod)

\section{Other}

CEE Central Eastern Europe(an)

CIS Commonwealth of Independent States

EU European Union

ICSID International Centre for Settlement of Investment Disputes

ILO International Labour Organization

TIE Transnationals Information Exchange 